\title{
Theoretical overview of clinical and pharmacological aspects of the use of etelcalcetide in diabetic patients undergoing hemodialysis
}

This article was published in the following Dove Press journal:

Drug Design, Development and Therapy

\author{
Jianzhen $\mathrm{Ye}^{\prime}$ \\ Guangrui Deng' \\ Feng $\mathrm{Gao}^{2}$ \\ 'Department of Endocrinology, \\ Huangzhou District People's Hospital, \\ Huanggang, People's Republic of \\ China; ${ }^{2}$ Department of Endocrinology, \\ Union Hospital, Tongji Medical \\ College, Huazhong University of \\ Science and Technology, Wuhan, \\ People's Republic of China
}

\begin{abstract}
Etelcalcetide is the first intravenous calcimimetic agent authorized for the treatment of secondary hyperparathyroidism (sHPT) in patients undergoing hemodialysis in Europe, the US, and Japan. The relationship between sHPT and diabetes resides on complex, bidirectional effects and largely unknown homeostatic mechanisms. Although $30 \%$ or more patients with end-stage renal disease are diabetics and about the same percentage of those patients suffer from sHPT associated with hemodialysis, no data on the specificities of the use of etelcalcetide in such patients are available yet. Regarding pharmacokinetic interactions, etelcalcetide may compete with oral hypoglycemics recommended for use in patients undergoing hemodialysis and insulins detemir and degludec, causing unexpected hypocalcemia or hypoglycemia. More importantly, hypocalcemia, a common side effect of etelcalcetide, may cause decompensation of preexisting cardiac insufficiency in diabetic patients or worsen dialysis-related hypotension and lead to hypotension-related cardiac events, such as myocardial ischemia. In diabetic patients, hypocalcemia may lead to dangerous ventricular arrhythmias, as both insulin-related hypoglycemia and hemodialysis prolong QT interval. Patients with diabetes, therefore, should be strictly monitored for hypocalcemia and associated effects. Due to an altered parathormone activity in this patient group, plasma calcium should be the preferred indicator of etelcalcetide effects. Until more clinical experience with etelcalcetide is available, the clinicians should be cautious when using this calcimimetic in patients with diabetes.
\end{abstract}

Keywords: glucose intolerance, renal impairment, calcimimetic, type 2 diabetes, hyperparathyroidism, parathyroid hormone

\section{Introduction}

Secondary hyperparathyroidism (sHPT), characterized by elevated levels of parathyroid hormone $(\mathrm{PTH})$ in response to derangements in the homeostasis of calcium, phosphate, and vitamin D, is a common complication of chronic kidney disease (CKD). ${ }^{1}$ Hypocalcemia, induced by phosphate retention and reduced calcitriol synthesis, typically occurs when the glomerular filtration rate (GFR) drops $<40 \mathrm{~mL} / \mathrm{min} / 1.73 \mathrm{~m}^{2}{ }^{2}$ This leads to hyperplasia of the parathyroid gland and a compensatory elevation of the circulating $\mathrm{PTH} .{ }^{3}$ Furthermore, CKD patients seem to have end-organ hyporesponsiveness to PTH, also known as PTH resistance, caused by an altered interaction of PTH with its receptor and/or downregulation of the PTH receptor. ${ }^{4}$ sHPT is present in $30 \%-40 \%$ of Stage 3 CKD patients and $50 \%-80 \%$ of Stage 4 CKD patients. ${ }^{5}$ Untreated sHPT eventually leads to renal osteodystrophy, as well as to accelerated vascular calcification and consequent myocardial infarctions, atrioventricular conduction disorders, and abnormalities in valvular function. ${ }^{6}$ Treatment options include the calcimimetic cinacalcet, vitamin D, and phosphate binders.
Correspondence: Feng Gao

Department of Endocrinology, Union

Hospital, Jiefang Avenue, Wuhan 430022,

Hubei, People's Republic of China

Tel +86 I397525208

Email gaofengwh@aliyun.com
Drug Design, Development and Therapy 2018:12 901-909

(c) (1) (2) ๑ $2018 \mathrm{Ye}$ et al. This work is published and licensed by Dove Medical Press Limited. The full terms of this license are available at https.//www.dovepress.com/terms.php cc. hereby accept the Terms. Non-commercial uses of the work are permitted without any further permission from Dove Medical Press Limited, provided the work is properly attributed. For permision for commercial use of this work, please see paragraphs 4.2 and 5 of our Terms (htpps://www.dovepress. com/terms.php). 
According to the 2008 UK renal registry report, diabetic nephropathy is a major cause of an end-stage renal disease affecting $28.9 \%$ of new adult patients starting renal replacement therapy, while in the US, diabetic nephropathy accounts for approximately $40 \%$ of patients with the end-stage renal disease. ${ }^{7,8}$ An Indian study showed that $>60 \%$ of type 2 diabetes mellitus (T2DM) patients with Stage 3 and 4 CKD suffer from sHPT, while $28.9 \%$ of T2DM patients undergoing outpatient hemodialysis have this disorder., ${ }^{90}$ On the other hand, in both healthy and renal failure patients, excess PTH impairs insulin release from pancreatic islets by an impaired glucose-induced calcium signal, additionally worsening glucose homeostasis. ${ }^{11}$ Therefore, the relationship between sHPT and diabetes is bidirectional, and its clinical repercussions are multifaceted, wide present, and alarming.

Given an already complicated medication regimen for many patients suffering from renal failure associated with diabetes and sHPT and a delicate link between the two diseases, a special attention should be paid to the treatment of diabetic patients with sHPT. In November 2016, the European Medicines Agency (EMA) approved etelcalcetide, the first intravenous calcimimetic agent, for the treatment of sHPT in adult patients with CKD undergoing hemodialysis, while the US Food and Drug Administration (FDA) and the Japanese Pharmaceuticals \& Medical Devices Agency (PMDA) did so at the beginning of 2017. ${ }^{12}$ Etelcalcetide offers several advantages over cinacalcet, an oral calcimimetic introduced in 2004 , such as better treatment adherence due to its administration within patients' hemodialysis sessions. However, clinical particularities of its use in a large population of diabetic patients undergoing hemodialysis and its potential pharmacological interactions with hypoglycemic agents remain largely unexplored. This review aims to identify all characteristics of etelcalcetide that could hold clinical relevance when administered to patients with diabetes. Given the limited amount of data on the use of etelecalcetide in diabetic dialysis patients, the nature of this review is narrative and theoretical, purely reflecting authors' concerns and considerations on this topic that might or not be relevant in the future.

\section{Etelcalcetide: dosing regimen, and pharmacokinetic and pharmacodynamic aspects}

Etelcalcetide is an anti-parathyroid agent which reduces PTH secretion through binding and activation of the calciumsensing receptor $(\mathrm{CaR})$ on the surface of the chief cell of the parathyroid gland. ${ }^{13}$ Etelcalcetide allosterically modulates the
CaR enhancing the activation of the receptor by extracellular calcium and decreasing PTH secretion which consequently leads to reductions in calcium and attenuation of post-dialytic phosphate elevation. ${ }^{13}$ The pharmacokinetics of etelcalcetide is linear, and following intravenous administration three times per week at the end of each hemodialysis session in CKD patients, etelcalcetide plasma levels reach steady state at 4 weeks after the initial dosing. Steady-state plasma levels are 2- to 3-fold higher than the initial ones. The drug is predominately bound to serum albumin (SA), following biotransformation in blood by reversible disulfide exchange with endogenous thiols. ${ }^{13}$ The effective half-life of 3-5 days is observed after intravenous administration three times per week at the end of a hemodialysis session. Hemodialysis eliminates the drug, and no body weight, gender, age, or race-related pharmacokinetic differences have been observed in adult patients studied. ${ }^{13}$

The recommended initial dose is $5 \mathrm{mg}$ administered by bolus injection three times per week. PTH should be measured after 4 weeks from initiation, and the dose titrated to establish an individualized regimen ranging from 2.5 to $15 \mathrm{mg}$ three times per week. In the maintenance phase, PTH should be measured every 1-3 months. Reduction in PTH levels correlates with plasma etelcalcetide concentrations in hemodialysis patients. If PTH is $<100 \mathrm{pg} / \mathrm{mL}$, the dose should be temporarily stopped and reinitiated at a lower dose once PTH returns to $>150 \mathrm{pg} / \mathrm{mL}$ and pre-hemodialysis serum corrected calcium $\geq 8.3 \mathrm{mg} / \mathrm{dL} .{ }^{13}$

Clinical efficacy and safety of etelcalcetide have been evaluated in two double-blind, placebo-controlled studies, and one double-blind, cinacalcet-controlled study, including 1,706 sHPT patients undergoing hemodialysis. ${ }^{14,15}$ The primary end point in all studies was the proportion of patients with $>30 \%$ reduction from baseline in PTH during the efficacy assessment period (defined as weeks 20-27 inclusive). Placebo-controlled studies demonstrated a significant difference in $>30 \%$ PTH reduction among patients receiving etelcalcetide and those treated with placebo, while the activecontrolled study showed non-inferiority to cinacalcet. ${ }^{14,15}$

\section{Pharmacological considerations Pharmacokinetic interactions}

In vitro studies showed that etelcalcetide is not a substrate for CYP450 enzymes and does not inhibit or induce them. ${ }^{16}$ Similarly, in in vitro studies, etelcalcetide was not a substrate of efflux and uptake transporter proteins and did not exhibit a potential to inhibit common transporter proteins. ${ }^{16}$ Pharmacokinetic alterations of etelcalcetide potentially 
induced by diabetes mellitus, such as an impaired drug absorption (owing to changes in subcutaneous adipose blood flow, muscle blood flow, and gastric emptying), biotransformation (owing to enzyme/transporter regulation involved in this process), and excretion (owing to nephropathy), cannot be expected as the drug is administered intravenously and it is almost completely eliminated by hemodialysis. ${ }^{17}$

As already mentioned, etelcalcetide is predominately bound to SA by reversible covalent binding, and therefore, its unbound fraction could be altered by hypoalbuminemia or drugs that compete for the same binding site on the SA molecule. Hypoalbuminemia in patients undergoing hemodialysis is attributed to protein-calorie malnutrition, decreased albumin synthesis, and extracorporal losses during hemodialysis, making a troublesome liaison with the impaired liver production of albumin during insulin deficiency. ${ }^{18,19}$ In such patients, increased plasma levels of an active fraction of etelcalcetide caused by hypoalbuminemia may cause an unexpected drop in PTH levels and subsequent hypocalcemia. Also, albumin binding of etelcalcetide may be altered by nonenzymatic glycation of plasma proteins, as in the case of sulfonylureas. ${ }^{20-23}$

\section{Oral hypoglycemic agents}

The 2005 American National Kidney Foundation Kidney Disease Outcomes Quality Initiative (NKF KDOQI) guidelines suggest that, in hemodialysis patients, newer insulin regimens and insulin preparations should be used rather than oral agents for glycemic control because of the lack of adequate data concerning the use of oral agents in hemodialysis patients. ${ }^{24}$ However, some clinicians prefer maintaining their patients on oral hypoglycemics after hemodialysis initiation, especially when they provide satisfying glycemic control.

Preferred oral hypoglycemics in hemodialysis patients have predominantly hepatic metabolism, inactive or weakly active metabolites that are excreted in the urine, and a low risk of hypoglycemia, as the pharmacokinetic properties of many of the available oral hypoglycemic agents are altered by kidney dysfunction. ${ }^{24}$ Oral antidiabetics recommended for use in patients undergoing hemodialysis are glipizide and repaglinide. ${ }^{25}$ Both of these drugs may compete with etelcalcetide at the protein-binding level. Glipizide's protein binding exceeds $99 \%$, while repaglinide, the preferred glinide in hemodialysis patients, is bound to albumin over $98 \% .^{26,27}$ At the moment, it is not known whether this protein-binding displacement could lead to clinically significant hypoglycemias and/or increased free concentrations of etelcalcetide and consequent hypocalcemias. However, the clinicians must keep these possibilities in mind when co-administering etelcalcetide with the aforementioned antidiabetic drugs as no interaction studies have been performed with etelcalcetide so far.

\section{Insulin and glucagon-like peptide I receptor agonists}

As the kidneys primarily excrete exogenous insulin, experts recommend an insulin dose reduction of $50 \%$ when estimated GFR is $<10 \mathrm{~mL} / \mathrm{min} / 1.73 \mathrm{~m}^{2} .{ }^{28}$ In many patients, peripheral insulin resistance improves upon the initiation of hemodialysis, and their insulin requirements are additionally reduced. ${ }^{29-31}$ Overall information about drug-drug interactions with insulin is limited, although there are data suggesting a clinically relevant increase (with oral antidiabetic products, pramlintide, angiotensin-converting enzyme inhibitors, fibrates, monoamine oxidase inhibitors, salicylates, etc.) and decrease in the hypoglycemic effect of insulin (with corticosteroids, diuretics, sympathomimetic agents, isoniazid, phenothiazine derivatives, protease inhibitors, atypical antipsychotic medications). ${ }^{32-36}$ The mechanisms responsible for these interactions are largely unknown.

When injected subcutaneously, insulin detemir and degludec extensively bind to albumin which appears to be responsible for low absorption from the subcutaneous depot of these drugs. ${ }^{37-39}$ Due to its high albumin binding, free concentration of etelcalcetide may be affected by its co-administration with these insulins. Liraglutide has been suggested as one of the glucagon-like peptide 1 receptor agonists that do not require dose adjustment in patients on hemodialysis. ${ }^{40}$ However, liraglutide is also the only drug from this group with high protein binding $(>98 \%)$, and awaiting interaction studies with etelcalcetide, the clinicians should be aware of the potential interaction between these two drugs. The list of hypoglycemic agents that could interact with etelcalcetide at the protein-binding level is provided in Table 1.

Table I Hypoglycemic agents with potential to interact with etelcalcetide at the protein-binding level

\begin{tabular}{lll}
\hline Drugs & $\begin{array}{l}\text { Albumin } \\
\text { binding (\%) }\end{array}$ & $\begin{array}{l}\text { Possible clinical } \\
\text { effect }\end{array}$ \\
\hline Oral hypoglycemic agents & & Hypocalcemia/hypoglycemia \\
$\quad$ Glipizide & $>99$ & \\
$\quad$ Repaglinide & $>98$ & \\
Insulins & & \\
$\quad$ Detemir & $>98$ & \\
Degludec & $>99$ & \\
GLP-I receptor agonists & \\
Liraglutide & $>98$ \\
\hline Abbreviation: GLP-I, glucagon-like peptide I.
\end{tabular}




\section{Pharmacodynamic interactions}

Among hypoglycemic agents recommended for use in patients with diabetes undergoing hemodialysis, there are no data that could suggest a potential pharmacodynamic interaction with etelcalcetide at the moment.

\section{Clinical considerations related to the use of etelcalcetide in diabetic patients}

\section{Parathormone activity in diabetes}

As already mentioned, $60 \%$ of T2DM patients with end-stage renal disease and $28.9 \%$ of T2DM patients undergoing outpatient hemodialysis suffer from sHPT. ${ }^{10}$ The principal reason for this high prevalence is kidney-related hyperphosphatemia and vitamin D deficiency, while hypomagnesemia (owing to poor dietary intake, increased magnesiuria, altered insulin metabolism, recurrent metabolic acidosis, metforminand diabetic neuropathy-related diarrhea, etc.) and hypoalbuminemia (owing to nephrotic syndrome, hemodialysis itself, poor dietary intake) significantly contribute. ${ }^{41}$ Despite the high prevalence of sHPT among diabetic patients with end-stage renal disease and patients on hemodialysis, studies which compared parathyroid function in diabetic and nondiabetic patients on hemodialysis found a significantly lower parathyroid activity in the diabetic group. Interestingly, all studies that addressed this topic identified lower parathormone serum levels in diabetic patients than in nondiabetic patients, while there were no significant differences in serum calcium and phosphorus levels between diabetics and nondiabetics. ${ }^{42-45}$ The explanation for these observations is still lacking. The main indicator of etelcalcetide's efficacy is PTH, which should be monitored, according to the manufacturer's recommendation, 4 weeks after the treatment initiation and every $1-3$ months in the maintenance phase. ${ }^{13}$

\section{Adynamic bone disease (ABD)}

$\mathrm{ABD}$ is a variety of renal osteodystrophy characterized by reduced osteoblasts and osteoclasts and markedly low bone turnover without osteoid accumulation. ${ }^{46}$ The absence of cellular activity and osteopenia are typically associated with low plasma PTH levels. ${ }^{47}$ In a bone biopsy study in hemodialysis patients, PTH plasma levels determined by immunoradiometric assay were highly predictive of ABD if $<120 \mathrm{pg} / \mathrm{mL}$, while levels $>450 \mathrm{pg} / \mathrm{mL}$ virtually excluded ABD. ${ }^{48}$ Nonetheless, patients with end-stage renal disease normally have PTH levels higher than those found in healthy population, and low bone formation rates have also been found in uremic patients with PTH levels within or above the normal range. ${ }^{49}$ Several preclinical studies showed a diminished calcemic response to PTH stimulation, which suggests a resistance to the action of PTH in patients with chronic renal failure, probably due to downregulation of cellular PTH/PTH-related protein receptor. ${ }^{49-51}$ Apart from the resistance to PTH, overtreatment of SHPT is another possible contributor to the ABD development. ${ }^{47}$

As stated in the Summary of Product Characteristics (SPC) of etelcalcetide, if PTH levels decrease below the recommended target range $(100 \mathrm{pg} / \mathrm{mL})$, the dose of this drug should be reduced or therapy discontinued.$^{13}$ However, while this recommendation may indeed result in the prevention of $\mathrm{ABD}$ in general population, patients with diabetes may require a different approach.

Studies have shown that serum markers of bone turnover, especially the formation markers, such as osteocalcin, are decreased in patients with diabetes. ${ }^{52,53}$ Moreover, bone histomorphometry has demonstrated that remodeling parameters such as bone formation rate and mineralizing surface are significantly lower in T2DM patients than controls indicating a low turnover state. ${ }^{54,55}$ When compared with their matched nondiabetic counterparts, patients with diabetes undergoing hemodialysis had significantly lower plasma PTH levels, mineralized bone area, osteoblastic osteoid, and bone formation rate. ${ }^{56}$ This is thought to be owing to higher levels of circulating sclerostin, an osteocyte product that negatively regulates bone formation, and the accumulation of advanced glycation end products that weaken the bone matrix. ${ }^{57-60}$ This suggests that the reduction or discontinuation of etelcalcetide in diabetic patients may be required at plasma PTH levels higher than those recommended by the manufacturer to prevent the ABD development. While awaiting studies addressing this important issue, instead of relying on plasma PTH levels for the prevention of ABD in diabetic patients undergoing hemodialysis, the clinicians should use histomorphometric parameters to get an overview upon bone metabolism.

\section{Decreased myocardial performance and congestive heart failure}

Several studies suggest that DM has direct adverse effects on the heart, independent of obstructive coronary artery disease, such as an increased left ventricle (LV) mass and wall thicknesses, reduced LV systolic chamber and myocardial function, and increased arterial stiffness. ${ }^{61-63}$ On the other hand, hypocalcemia, a common side effect of etelcalcetide, is a known cause of a reversible heart failure as an intracellular increase of calcium ions plays a crucial role in the initiation 
of cross-bridging between actin and myosin and the consequent contraction of cardiomyocytes ${ }^{64-66}$ Hypocalcemiainduced decompensation of a preexisting cardiac insufficiency in diabetic patients has been described in the literature ${ }^{67} \mathrm{No}$ specific characteristics of etelcalcetide use in diabetic patients have been reported so far, and although the SPC of etelcalcetide states that "serum calcium levels should be monitored in patients with a history of congestive heart failure while being treated with etelcalcetide", there are no specific directives regarding patients with diabetes, stages of heart failure, or associated conditions, such as coronary disease. ${ }^{13}$ Therefore, in the presence of coexisting factors leading to heart failure, such as diabetes, the clinicians must strictly monitor serum calcium when using etelcalcetide and never overlook etelcalcetide-induced hypocalcemia as a possible trigger of cardiac events.

\section{Hypotension}

In clinical studies that evaluated efficacy and safety of etelcalcetide, hypotension was identified as a common side effect of this drug. ${ }^{14,15}$ The SPC of etelcalcetide states that "hypotension may be associated with significant reductions in serum calcium levels", but the performed studies did not address the correlation between hypocalcemia and hypotension..$^{13}$ Therefore, a direct hypotensive effect of etelcalcetide cannot be excluded. Etelcalcetide-induced hypocalcemia has an essential significance for patients undergoing hemodialysis, especially those with coexisting cardiovascular disturbances, such as the case with diabetic patients. Hemodialysis hypotension, episodic (defined as a sudden drop of systolic blood pressure $<90 \mathrm{mmHg}$ or of at least $20 \mathrm{mmHg}$ with accompanying clinical symptoms) or chronic (persistent hypotension in which interdialytic systolic blood pressure is maintained at $<90-100 \mathrm{mmHg}$ ), is caused by several factors such as aggressive reduction of circulating blood volume owing to ultrafiltration, rapid decrease in extracellular osmolality associated with sodium removal, and coexisting imbalance between ultrafiltration and plasma refilling. ${ }^{68,69}$ Acute intradialytic hypotonia reduces coronary blood flow and may lead to heart failure, cardiac arrhythmia, or even cardiac arrest, while recurrent or chronic hypotension can damage other vital organs such as the brain and gastrointestinal tract. ${ }^{70}$ Patients with diabetes are particularly prone to hemodialysis hypotension because of autonomic neuropathy and impairment in cardiopulmonary receptors and arterial pressoreceptors and are at greater risk of hypotension-related cardiovascular complications. ${ }^{69}$ Therefore, the clinicians must carefully monitor etelcalcetide-treated patients for hypotension, especially those with preexisting hypotonia/ hypoperfusion. Due to many potential complications related to hypocalcemia in diabetic patients treated with etelcalcetide, the clinicians may consider using cinacalcet instead, as this drug causes less hypocalcemia than etelcalcetide. ${ }^{15}$

\section{Hepatic impairment}

The entire spectrum of liver disease (abnormal liver enzymes, nonalcoholic fatty liver disease, cirrhosis, hepatocellular carcinoma, acute liver failure) is seen in patients with diabetes. ${ }^{71,72}$ Although it has been shown that the biotransformation of etelcalcetide occurs in blood and not in the liver, theoretically, impairment of the hepatic functional status may affect etelcalcetide's pharmacokinetics due to its high protein binding, primarily through hypoalbuminemia and albumin-binding displacement. ${ }^{13,71}$ Currently, there are no data regarding the use of etelcalcetide in patients with impaired liver function. The manufacturer does not discourage its use in such patients, but clearly states that the drug has not been studied in this group. Therefore, these patients must be under increased medical surveillance when treated with etelcalcetide. Clinical considerations related to the use of etelcalcetide in diabetic patients are summarized in Table 2 .

\section{Adverse reactions QT interval prolongation}

A prolonged heart rate-corrected QTc interval is defined as $>450 \mathrm{~ms}$ in men and $470 \mathrm{~ms}$ in women, and it is recognized as a well-known risk factor for ventricular arrhythmias and sudden cardiac death. ${ }^{73}$ Etelcalcetide was shown to cause QTc prolongation in treated patients due to hypocalcemia, and its SPC emphasizes that

\section{the levels of calcium should be closely monitored in patients with congenital long QT syndrome, previous history of QT prolongation, family history of long QT syndrome or sudden cardiac death and other conditions that predispose to QT prolongation and ventricular arrhythmia. ${ }^{13}$}

This may impose a great obstacle to the use of this drug in diabetic patients on insulin treatment; namely, the QTc interval is characteristically prolonged in diabetes and has been related to unexplained cases of sudden overnight death in diabetic patients on insulin treatment. ${ }^{73-75}$ Even nondiabetic persons with hyperinsulinemia were found to have QTc interval prolongation, and this effect was observed in both acute and chronic states of hyperinsulinemia. ${ }^{76,77}$ Two principal mechanisms by which insulin affects the QTc interval have 
Table 2 Hypothetical influence of the treatment of secondary hyperparathyroidism with etelcalcetide versus cinacalcet as a function of clinical alterations associated with diabetes mellitus

\begin{tabular}{|c|c|c|}
\hline Clinical alterations in diabetes & Possible influence of etelcalcetide & Possible influence of cinacalcet \\
\hline Lower plasma PTH levels & More rigorous monitoring for the & Requires more strict monitoring for the prevention \\
\hline Lower bone formation rate & prevention of $A B D$ in diabetic patients & of $A B D$ in diabetic patients \\
\hline Prolonged QTc interval & $\begin{array}{l}\text { Greater risk of ventricular arrhythmias } \\
\text { due to hypocalcemia in diabetic patients }\end{array}$ & $\begin{array}{l}\text { Greater risk of ventricular arrhythmias due to } \\
\text { hypocalcemia in diabetic patients, but less risk of } \\
\text { hypocalcemia than with etelcalcetide }\end{array}$ \\
\hline $\begin{array}{l}\text { Decreased myocardial } \\
\text { performance and cardiac } \\
\text { insufficiency }\end{array}$ & $\begin{array}{l}\text { Decompensation due to hypocalcemia } \\
\text { in diabetic patients }\end{array}$ & $\begin{array}{l}\text { Decompensation due to hypocalcemia in diabetic } \\
\text { patients, but less risk of hypocalcemia than with } \\
\text { etelecalcetide }\end{array}$ \\
\hline $\begin{array}{l}\text { Greater risk of hemodialysis } \\
\text { hypotension }\end{array}$ & $\begin{array}{l}\text { Worsening of hypotension due to } \\
\text { hypocalcemia in diabetic patients }\end{array}$ & $\begin{array}{l}\text { Worsening of hypotension due to hypocalcemia in } \\
\text { diabetic patients, but less risk of hypocalcemia than } \\
\text { with etelcalcetide }\end{array}$ \\
\hline Higher rate of hepatic impairment & $\begin{array}{l}\text { Hypoalbuminemia and albumin-binding } \\
\text { displacement may cause an increase in } \\
\text { etelcalcetide plasma concentrations }\end{array}$ & $\begin{array}{l}\text { A } 2 \text { - to } 4 \text {-fold increase in plasma concentrations in } \\
\text { moderate-to-severe insufficiency } \\
\text { Cinacalcet protein binding not affected by hepatic } \\
\text { insufficiency }{ }^{95} \\
\text { Plasma concentrations significantly affected by } \\
\text { smoking and other drugs metabolized by CYP2D695 }\end{array}$ \\
\hline $\begin{array}{l}\text { Changes in subcutaneous adipose } \\
\text { blood flow, muscle blood flow, } \\
\text { and gastric emptying }\end{array}$ & No interference & Possibly decreased absorption of cinacalcet \\
\hline
\end{tabular}

Abbreviations: ABD, adynamic bone disease; PTH, parathyroid hormone; QTc, corrected QT interval.

been proposed: direct action on the cell membrane to shift extracellular potassium into the cytoplasm by increasing the activity of the $\mathrm{Na}^{+} / \mathrm{K}^{+}$-ATPase pump and sympathetic stimulation by hypoglycemia and hypokalemia. ${ }^{78,79}$ As reported in a recent study that investigated the effects of hypoglycemia induced by the administration of human insulin to diabetic patients, insulin-induced hypoglycemia causes a significant QT prolongation in comparison with baseline values and is associated with hypokalemia and sympathoadrenal activation. ${ }^{80}$ In addition to these findings, many studies have confirmed a significant QTc prolongation in hemodialysis patients compared with controls independently from glucose disturbances and insulin administration. ${ }^{81-85}$ Knowing that hypoglycemia is frequent in insulin-treated diabetic patients undergoing hemodialysis and that this procedure itself can induce QT prolongation, the clinicians should strictly monitor these patients for this adverse effect that may lead to ventricular arrhythmias when combined with other QT-prolonging medicines, such as etelcalcetide. Again, it is important to say that the nature of such reasoning is purely speculative and theoretical.

In studies designed to evaluate clinical efficacy and safety of repaglinide, arrhythmias were observed at $\leq 1 \%$ and no more frequently with this drug than with comparator drugs. ${ }^{27}$ Nonetheless, repaglinide exerts its effect by closing ATP-dependent potassium channels, and in in vitro ion channel studies, repaglinide was shown to inhibit all of the tested ionic currents in a concentration-dependent manner, significantly prolonging the action potential duration in isolated rabbit Purkinje fibers. ${ }^{86}$ Although it has been shown that repaglinide's pharmacokinetics and safety are not influenced by severe renal impairment, there are no data regarding its QT interval-prolonging potential when administered with other drugs (ie, etelcalcetide) and in situations (ie, hemodialysis) that promote the appearance of this side effect. ${ }^{87}$

\section{Gastrointestinal adverse reactions}

Clinical studies evaluating the clinical safety of etelcalcetide revealed that this drug causes nausea and vomiting in $>10 \%$ of treated patients, while diarrhea occurs in $>5 \%,{ }^{14,15}$ Nausea and diarrhea are described as common adverse effects ( $\geq 1 / 100$ to $<1 / 10$ ) of glipizide, while diarrhea commonly occurs with repaglinide. ${ }^{26,27}$ Clinicians should bear in mind that these effects may be potentiated when these hypoglycemics are co-administrated with etelcalcetide.

\section{Calcimimetics: effect on pancreas}

The extracellular CaR is expressed in many other tissues besides the parathyroid gland, including pancreatic islets of Langerhans, exerting functions not associated with plasma calcium homeostasis. ${ }^{88-90}$ It is thought that, in the pancreas, the $\mathrm{CaR}$ mediates cell-to-cell communication 
within islets to coordinate insulin secretory responses, through local increases in the concentration of extracellular $\mathrm{Ca}^{2+}{ }^{21}$ In glucose-induced insulin secretion, free $\mathrm{Ca}^{2+}$ ions are co-released with insulin, increasing the local concentration of extracellular calcium in the intra-islet space. These changes act in a paracrine fashion; detected by the extracellular $\mathrm{CaR}$ on adjacent cells, the signal propagates across the islet, enhancing insulin secretion..$^{92}$ This mechanism may be partially responsible for the higher prevalence of diabetes among patients with primary hyperparathyroidism..$^{93}$

In in vitro models, it has been shown that the activation of $\mathrm{CaR}$ using receptor-specific calcimimetics enhances insulin secretion from human islets. ${ }^{90,94}$ This enhancement was rapid and transient, suggesting that calcimimetics affect the insulin secretory process and it occurred without previous stimulation by glucose. ${ }^{90,94}$ Currently, it is not clear whether etelcalcetide or its older counterpart, cinacalcet, may influence glucose or insulin levels in patients with diabetes undergoing hemodialysis. The clinical trials performed with etelcalcetide do not provide any data related to the parameters of glucose metabolism in the included patients, including those with diabetes. The expression of a functional $\mathrm{CaR}$ within human pancreatic islets suggests that calcimimetics may have wider implications for tissues outside the normal targets for control of systemic calcium, and the researchers need to fully explore possible consequences of this.

\section{Conclusion}

While the clinical studies with etelcalcetide did include patients with controlled diabetes, they did not place attention on this patient group regarding etelcalcetide monitoring or safety aspects, neither did they report on possible interactions between hypoglycemic agents and etelcalcetide. Until more clinical experience with etelcalcetide is available and interaction studies are performed, the clinicians must take into account that pharmacokinetic interactions with etelcalcetide may occur at the SA-binding level with the two recommended oral hypoglycemics, glipizide and repaglinide, as well as with insulins detemir and degludec, and the clinicians should avoid their use. While an overall potential of etelcalcetide for pharmacokinetic and pharmacodynamic interactions with hypoglycemic agents seems to be low, its drug-disease profile deserves much more attention. Plasma PTH levels are lower in diabetic patients on hemodialysis than in their nondiabetes counterparts for unknown reasons, but interestingly, calcemia remains the same between the two groups. Also, these lower plasma PTH levels are associated with a greater degree of reduction of mineralized bone area, osteoblastic osteoid, and bone formation rate in diabetic patients. On the other hand, etelcalcetide-induced hypocalcemia and its consequences are of special importance in patients suffering from diabetes due to the fact that this patient group already has cardiovascular disturbances, such as cardiac failure, ischemic heart disease, and hypotonia due to autonomic neuropathy and impairment in cardiopulmonary and arterial pressoreceptors and is, therefore, at greater risk of decompensation of the existing disease. The clinicians should put an extreme attention to the possibility of QTc interval prolongation and ventricular arrhythmias in diabetic patients treated with etelcalcetide, as insulin treatment/insulin-induced hypoglycemia has been linked with QTc prolongation and hypocalcemia is a known risk factor for this ECG alteration.

In conclusion, until clinical data refute our current theoretical concerns, the clinicians should avoid the use of oral hypoglycemic agents in combination with etelcalcetide and strictly monitor plasma levels and histomorphometric parameters of diabetic patients, at the same time surveilling them for cardiovascular events.

\section{Disclosure}

The authors report no conflicts of interest in this work.

\section{References}

1. Yuen NK, Ananthakrishnan S, Campbell MJ. Hyperparathyroidism of renal disease. Perm J. 2016;20(3):78-83.

2. Levin A, Bakris GL, Molitch M, et al. Prevalence of abnormal serum vitamin D, PTH, calcium, and phosphorus in patients with chronic kidney disease: results of the study to evaluate early kidney disease. Kidney Int. 2007;71(1):31-38.

3. Martin KJ, González EA. Metabolic bone disease in chronic kidney disease. J Am Soc Nephrol. 2007;18(3):875-885.

4. Evenepoel P, Bover J, Ureña Torres P. Parathyroid hormone metabolism and signaling in health and chronic kidney disease. Kidney Int. 2016; 90(6):1184-1190.

5. Cheng S, Coyne D. Secondary hyperparathyroidism in the diabetic patient with chronic kidney disease. US Endocrinol. 2005;1:39-42.

6. Goodman WG. The consequences of uncontrolled secondary hyperparathyroidism and its treatment in chronic kidney disease. Semin Dial. 2004;17(3):209-216.

7. Ansell D, Feehally J, Feest TG, Tomson C, Williams AJ, Warwick G. UK Renal Registry 11th Annual Report. Bristol: The Renal Association; 2008. Available from: https://www.renalreg.org/wp-content/uploads/ 2014/09/Report2008.pdf. Accessed November 15, 2017.

8. U.S. Renal Data System. USRDS 2011 Annual Data Report: Atlas of Chronic Kidney Disease and End-Stage Renal Disease in the United States. Bethesda, MD: National Institutes of Health, National Institute of Diabetes and Digestive and Kidney Diseases; 2011.

9. Arévalo-Lorido JC, Carretero-Gómez J, García-Sánchez F, et al. Secondary hyperparathyroidism prevalence and profile, between diabetic and non-diabetic patients with stage 3 to 4 chronic kidney disease attended in internal medicine wards. MiPTH study. Diabetes Metab Syndr. 2016; 10(2 Suppl 1):S16-S21.

10. Chua CC, Rivero W, Gutierez MJ, Jasul GV. Prevalence of secondary hyperparathyroidism among outpatient type 2 diabetic patients undergoing hemodialysis in a tertiary hospital. Philipp J Intern Med. 2010; 48(1):4-8 
11. Massry SG. Sequence of cellular events in pancreatic islets leading to impaired insulin secretion in chronic kidney disease. J Ren Nutr. 2011; 21(1):92-99.

12. Hamano N, Komaba N, Fukagawa M. Etelcalcetide for the treatment of secondary hyperparathyroidism. Expert Opin Pharmacother. 2017;18(5):529-534.

13. Parsavib ${ }^{\circledR}$ (etelacetide) solution for injection [prescribing information]. Breda: Amgen Europe B.V.; 2016.

14. Block GA, Bushinsky DA, Cunningham J, et al. Effect of etelcalcetide vs placebo on serum parathyroid hormone in patients receiving hemodialysis with secondary hyperparathyroidism: two randomized clinical trials. JAMA. 2017;317(2):146-155.

15. Block GA, Bushinsky DA, Cheng S, et al. Effect of etelcalcetide vs cinacalcet on serum parathyroid hormone in patients receiving hemodialysis with secondary hyperparathyroidism: a randomized clinical trial. JAMA. 2017;317(2):156-164.

16. Subramanian R, Zhu X, Kerr SJ, et al. Nonclinical pharmacokinetics, disposition, and drug-drug interaction potential of a novel d-amino acid peptide agonist of the calcium-sensing receptor AMG 416 (etelcalcetide). Drug Metab Dispos. 2016;44(8):1319-1331.

17. Dostalek M, Akhlaghi F, Puzanovova M. Effect of diabetes mellitus on pharmacokinetic and pharmacodynamic properties of drugs. Clin Pharmacokinet. 2012;51(8):481-499.

18. Kaysen GA, Rathore V, Shearer GC, Depner TA. Mechanisms of hypoalbuminemia in hemodialysis patients. Kidney Int. 1995;48(2): 510-516.

19. Feo PD, Gaisano MG, Haymond MW. Differential effects of insulin deficiency on albumin and fibrinogen synthesis in humans. JClin Invest. 1991;88(3):833-840.

20. Basiaga SB, Hage DS. Chromatographic studies of changes in binding of sulfonylurea drugs to human serum albumin due to glycation and fatty acids. J Chromatogr B. 2010;878(30):3193-3197.

21. Joseph KS, Anguizola J, Hage DS. Binding of tolbutamide to glycated human serum albumin. J Pharm Biomed Anal. 2011;54(2):426-432.

22. Matsuda R, Anguizola J, Joseph KS. High-performance affinity chromatography and the analysis of drug interactions with modified proteins: binding of gliclazide with glycated human serum albumin. Anal Bioanal Chem. 2011;401(9):2811-2819.

23. Anguizola J, Joseph KS, Barnaby OS, et al. Development of affinity microcolumns for drug-protein binding studies in personalized medicine: interactions of sulfonylurea drugs with in vivo glycated human serum albumin. Anal Chem. 2013;85(9):4453-4460.

24. K/DOQI Workgroup. K/DOQI clinical practice guidelines for cardiovascular disease in hemodialysis patients. Am J Kidney Dis. 2005; 45(4 Suppl 3):S1-S153.

25. Reilly JB, Berns JS. Selection and dosing of medications for management of diabetes in patients with advanced kidney disease. Semin Dial. 2010;23(2):163-168.

26. Januvia ${ }^{\circledR}$ (glipizide) film-coated tablets [prescribing information]. Hoddesdon: Merck Sharp \& Dohme Ltd; 2007.

27. NovoNorm ${ }^{\circledR}$ (repaglinide) tablets [prescribing information]. Bagsværd: Novo Nordisk A/S; 1998.

28. Charpentier G, Riveline JP, Varroud-Vial M. Management of drugs affecting blood glucose in diabetic patients with renal failure. Diabetes Metab. 2000;26(Suppl 4):73-85.

29. DeFronzo RA, Tobin JD, Rowe JW, Andres R. Glucose intolerance in uremia. Quantification of pancreatic beta cell sensitivity to glucose and tissue sensitivity to insulin. J Clin Invest. 1978;62(2):425-435.

30. Dzurik R, Spustova V, Lajdova I. Inhibition of glucose utilization in isolated rat soleus muscle by pseudouridine: implications for renal failure. Nephron. 1993;65(1):108-110.

31. McCaleb ML, Izzo MS, Lockwood DH. Characterization and partial purification of a factor from uremic human serum that induces insulin resistance. J Clin Invest. 1985;75(2):391-396.

32. Humalog ${ }^{\circledR}$ (insulin lispro) injection [prescribing information]. Indianapolis, IN: Eli Lilly and Company; 2011.

33. NovoLog ${ }^{\circledR}$ (insulin aspart) injection [prescribing information]. Princeton, NJ: Novo Nordisk Inc; 2011.
34. Apidra ${ }^{\circledR}$ (insulin glulisine) injection [prescribing information]. Bridgewater, NJ: Sanofi-Aventis; 2009.

35. Helms KL, Kelley KW. Insulin glulisine: an evaluation of its pharmacodynamic properties and clinical application. Ann Pharmacother. 2009;43(4):658-668

36. Lantus ${ }^{\circledR}$ (insulin glargine) injection [prescribing information]. Bridgewater, NJ: Sanofi-Aventis; 2007.

37. Levemir $^{\circledR}$ (insulin detemir) injection [prescribing information]. Bagsvaerd: Novo Nordisk AS; 2015.

38. Tresiba ${ }^{\circledR}$ (insulin degludec) injection [prescribing information]. Bagsvaerd: Novo Nordisk AS; 2013.

39. Havelund S, Plum A, Ribel U, et al. The mechanism of protraction of insulin detemir, a long-acting, acylated analog of human insulin. Pharm Res. 2004;21(8):1498-1504.

40. Osonoi T, Saito M, Tamasawa A, et al. Effect of hemodialysis on plasma glucose profile and plasma level of liraglutide in patients with type 2 diabetes mellitus and end-stage renal disease: a pilot study. PLoS One. 2014;9(12):e113468

41. Liamis G, Liberopoulos E, Barkas F, Elisaf M. Diabetes mellitus and electrolyte disorders. World J Clin Cases. 2014;2(10):488-496.

42. Inaba M, Okuno S, Nagasue K, et al. Impaired secretion of parathyroid hormone is coherent to diabetic hemodialyzed patients. Am J Kidney Dis. 2001;8(4 Suppl 1):S139-S142.

43. Guh JY, Chen HC, Chuang HY, Huang SC, Chien LC, Lai YH. Risk factors and risk for mortality of mild hypoparathyroidism in hemodialysis patients. Am J Kidney Dis. 1997;29(6):862-865.

44. Vincenti F, Arnaud SB, Recker R, et al. Parathyroid and bone response of the diabetic patient to uremia. Kidney Int. 1984;25(4): 677-682.

45. Nasri H. Impact of diabetes mellitus on parathyroid hormone in hemodialysis patients. J Parathyr Dis. 2013;1(1):9-11.

46. Brandenburg VM, Floege J. Adynamic bone disease - bone and beyond. NDT Plus. 2008;1(3):135-147.

47. Coen G. Adynamic bone disease: an update and overview. J Nephrol. 2005;18(2):117-122.

48. Torres A, Lorenzo V, Hernandez D, et al. Bone disease in prehemodialysis, hemodialysis, and CAPD patients: evidence of a better bone response to PTH. Kidney Int. 1995;47(5):1434-1442.

49. Picton ML, Moore PR, Mawer EB, et al. Down-regulation of human osteoblast PTH/PTHrP receptor $\mathrm{mRNA}$ in end-stage renal failure. 2000; 58(4):1440-1449.

50. Martin GT, Morrissey KJ, Slatopolsky E. Role of 1,25 dihydroxyvitamin on skeletal resistance to parathyroid hormone. Kidney Int. 1987; 32(6):801-807.

51. Bover J, Jara A, Trinidad P, Rodriguez M, Martin Malo A, Felsenfeld AJ. The calcaemic response to PTH in the rat: effect of elevated PTH levels and uremia. Kidney Int. 1994;46:310-317.

52. Rubin MR. Bone cells and bone turnover in diabetes mellitus. Curr Osteoporos Rep. 2015;13(3):186-191.

53. Dobnig H, Piswanger-Sölkner JC, Roth M, et al. Type 2 diabetes mellitus in nursing home patients: effects on bone turnover, bone mass, and fracture risk. J Clin Endocrinol Metab. 2006;91(9): 3355-3363.

54. Krakauer JC, McKenna MJ, Buderer NF, Rao DS, Whitehouse FW, Parfitt AM. Bone loss and bone turnover in diabetes. Diabetes. 1995;44(7):775-782.

55. Manavalan JS, Cremers S, Dempster DW, et al. Circulating osteogenic precursor cells in type 2 diabetes mellitus. J Clin Endocrinol Metab. 2012;97(9):3240-3250.

56. Andress DL, Hercz G, Kopp JB, et al. Bone histomorphometry of renal osteodystrophy in diabetic patients. J Bone Miner Res. 1987;2(6): 525-531.

57. Gennari L, Merlotti D, Valenti R, et al. Circulating sclerostin levels and bone turnover in type 1 and type 2 diabetes. J Clin Endocrinol Metab. 2012;97(5):1737-1744.

58. García-Martín A, Rozas-Moreno P, Reyes-García R, et al. Circulating levels of sclerostin are increased in patients with type 2 diabetes mellitus. J Clin Endocrinol Metab. 2012;97(1):234-241. 
59. Saito M, Fujii K, Soshi S, Tanaka T. Reductions in degree of mineralization and enzymatic collagen cross-links and increases in glycationinduced pentosidine in the femoral neck cortex in cases of femoral neck fracture. Osteoporos Int. 2006;17(7):986-995.

60. Yamamoto M, Yamaguchi T, Yamauchi M, Yano S, Sugimoto T. Serum pentosidine levels are positively associated with the presence of vertebral fractures in postmenopausal women with type 2 diabetes. $J$ Clin Endocrinol Metab. 2008;93(3):1013-1019.

61. Abenavoli T, Rubler S, Fisher VJ, Axelrod HI, Zuckerman KP. Exercise testing with myocardial scintigraphy in asymptomatic diabetic males. Circulation. 1981;63(1):54-64.

62. Factor SM, Minase T, Sonnenblick EM. Clinical and morphologic features of human diabetic cardiomyopathy. Am Heart J. 1980;99(4): 446-458.

63. Devereux RB, Roman MJ, Paranicas M, et al. Impact of diabetes on cardiac structure and function. The strong heart study. Circulation. 2000; 101(19):2271-2276.

64. Levine SN, Rheams CN. Hypocalcemic heart failure. Am J Med. 1985; 78(6 Pt 1):1033-1055.

65. Solzbach U, Kitterer HR, Haas H. Reversible congestive heart failure in severe hypocalcemia. Herz. 2010;35(7):507-510.

66. Maiya S, Sullivan I, Allgrove J, et al. Hypocalcaemia and vitamin D deficiency: an important, but preventable, cause of life-threatening infant heart failure. Heart. 2008;94(5):581-584

67. Lin CS, Lin SH, Cheng SM, Yang SP, Tsao TP. Reversible heart failure in a hypocalcemic patient. Acta Cardiol Sin . 2009;25:47-51.

68. Sulowicz W, Radziszewski A. Pathogenesis and treatment of hemodialysis hypotension. Kidney Int. 2006;70:S36-S39.

69. Dheenan S, Henrich WL. Preventing hemodialysis hypotension: a comparison of usual protective maneuvers. Kidney Int. 2001;59:1175-1181.

70. Santoro A, Mancini E, Basile C, et al. Blood volume controlled hemodialysis in hypotension-prone patients: a randomized, multicenter controlled trial. Kidney Int. 2002;62(3):1034-1045.

71. Palatini P, Orlando R, De Martin S. The effect of liver disease on inhibitory and plasma protein-binding displacement interactions: an update. Expert Opin Drug Metab Toxicol. 2010;6(10):1215-1230.

72. Rodighiero V. Effects of liver disease on pharmacokinetics. An update. Clin Pharmacokinet. 1999;37(5):399-431.

73. Kahn JK, Sisson JC, Vinik AI. QT interval prolongation and sudden cardiac death in diabetic autonomic neuropathy. J Clin Endocrinol Metab. 1987;64(4):751-754.

74. Brown DW, Giles WH, Greenlund KJ, Valdez R, Croft JB. Impaired fasting glucose, diabetes mellitus, and cardiovascular disease risk factors are associated with prolonged QTc duration. Results from the Third National Health and Nutrition Examination Survey. J Cardiovasc Risk. 2001;8(4):227-233.

75. Solini A, Passaro A, D’Elia K, Calzoni F, Alberti L, Fellin R. The relationship of plasma glucose and electrocardiographic parameters in elderly women with different degrees of glucose tolerance. Aging. 2000; 12(4):249-255.

76. Dekker JM, Feskens EJ, Schouten EG, Klootwijk P, Pool J, Kromhout D. QTc duration is associated with levels of insulin and glucose intolerance. The Zutphen Elderly Study. Diabetes. 1996;45(3):376-380.

77. Laitinen T, Vauhkonen I, Niskanen L, Hartikainen J, Uusitupa M, Laakso M. Prolonged corrected QT interval is associated with acute and chronic hyperinsulinemia in nondiabetic subjects. Diabetes Care. 2003; 26(8):2480-2481.

Drug Design, Development and Therapy

\section{Publish your work in this journal}

Drug Design, Development and Therapy is an international, peerreviewed open-access journal that spans the spectrum of drug design and development through to clinical applications. Clinical outcomes, patient safety, and programs for the development and effective, safe, and sustained use of medicines are the features of the journal, which
78. Marfella R, Rossi F, Giugliano D. Hyperglycemia and QT interval: time for re-evaluation. Diabetes Nutr Metab. 2001;14(2):63-65.

79. Gastaldelli A, Emdin M, Conforti F, Camastra S, Ferrannini E. Insulin prolongs the QTc interval in humans. Am J Physiol Cell Physiol. 2000; 279(6):R2022-R2025.

80. Kacheva S, Karges B, Göller K, Marx N, Mischke K, Karges W. QT prolongation caused by insulin-induced hypoglycaemia - an interventional study in 119 individuals. Diabetes Res Clin Pract. 2017; 123:165-172.

81. Morris ST, Galiatsou E, Stewart GA, Rodger RS, Jardine AG. QT dispersion before and after hemodialysis. J Am Soc Nephrol. 1999; 10(1):160-163.

82. Lorincz I, Matyus J, Zilahi Z, Kun C, Karányi Z, Kakuk G. QT dispersion in patients with end-stage renal failure and during hemodialysis. J Am Soc Nephrol. 1999;10(6):1297-1302.

83. Yildiz A, Akkaya V, Sahin S, et al. QT dispersion and signal-averaged electrocardiogram in hemohemodialysis and CAPD patients. Perit Dial Int. 2001;21(2):186-192.

84. Covic A, Diaconita M, Gusbeth-Tatomir P, et al. Hemodialysis increases QTc interval but not QTc dispersion in ESRD patients without manifest cardiac disease. Nephrol Dial Transplant. 2002;17(12): 2170-2177.

85. Malhis M, Al-Bitar S, Farhood S, Zaiat KA. Changes in QT intervals in patients with end-stage renal disease before and after hemodialysis. Saudi J Kidney Dis Transplant. 2010;21(3):460-465.

86. Leei H, Park S, Kim K. The effects of repaglinide on cardiac action potential and ion channels. In: 37th Congress of IUPS; 2013; Birmingham. Available from: http://www.physoc.org/proceedings/abstract/Proc $\% 20$ 37th\%20IUPSPCA058. Accessed November 24, 2017.

87. Marbury TC, Ruckle JL, Hatorp V, et al. Pharmacokinetics of repaglinide in subjects with renal impairment. Clin Pharmacol Ther. 2000;67(1):7-15.

88. Rasschaert J, Malaisse WJ. Expression of the calcium-sensing receptor in pancreatic islet B-cells. Biochem Biophys Res Commun. 1999; 264(3):615-618

89. Squires PE, Harris TE, Persaud SJ, Curtis SB, Buchan AM, Jones PM. The extracellular calcium-sensing receptor on human beta-cells negatively modulates insulin secretion. Diabetes. 2000;49(3): 409-407.

90. Gray E, Muller D, Squires PE, et al. Activation of the extracellular calcium-sensin receptor initiates insulin secretion from human islets of Langerhans: involvement of protein kinases. J Endocrinol. 2006; 190(3):703-710.

91. Jones PM, Kitsou-Mylona I, Gray E, Squires PE, Persaud SJ. Expression and function of the extracellular calcium-sensing receptor in pancreatic b-cells. Arch Physiol Biochem. 2007;113(3): 98-103.

92. Hodgkin MN, Hills CE, Squires PE. The calcium-sensing receptor and insulin secretion: a role outside systemic control 15 years on. J Endocrinol. 2008;199(1):1-4.

93. Taylor WH, Khaleeli AA. Coincident diabetes mellitus and primary hyperparathyroidism. Diabetes Metab Res Rev. 2001;17(3):75-180.

94. Trivedi R, Mithal A, Chattopadhyay N. Recent updates on the calciumsensing receptor as a drug target. Curr Med Chem. 2008;15(2): $178-186$.

95. Mimpara ${ }^{\circledR}$ (cinacalcet) film-coated tablets [prescribing information]. Breda: Amgen Europe B.V.; 2009. has also been accepted for indexing on PubMed Central. The manuscript management system is completely online and includes a very quick and fair peer-review system, which is all easy to use. Visit http://www.dovepress.com/testimonials.php to read real quotes from published authors. 